\title{
CORRELATION OF LENGTH OF FEMUR WITH ITS PROXIMAL FRAGMENTS- A MORPHOMETRIC STUDY
}

Suja Robert Joseph Sarasammal', Latha Sreedhar Lekshmy Sreedhar'2, Aswathy Maria Oommen ${ }^{3}$, Sheena K. S4, Sreekumar Rajasekharan ${ }^{5}$, Swapna T6

${ }^{1}$ Assistant Professor, Department of Anatomy, Government Medical College, TVPM, Kerala. ${ }^{2}$ Associate Professor, Department of Anatomy, Government Medical College, TVPM, Kerala. ${ }^{3}$ Assistant Professor, Department of Anatomy, Government Medical College, TVPM, Kerala. ${ }^{4}$ Assistant Professor, Department of Anatomy, Government Medical College, TVPM, Kerala. ${ }^{5}$ Assistant Professor, Department of Anatomy, Government Medical College, TVPM, Kerala. ${ }^{6}$ Assistant Professor, Department of Anatomy, Government Medical College, TVPM, Kerala.

ABSTRACT
BACKGROUND
The stature of an individual is used to establish the identity of a person medicolegally. The stature is calculated from the length of
long bones. This study is an effort to derive regression equations for the reconstruction of length of femur from its fragments.

\section{MATERIALS AND METHODS}

This is a descriptive study using hundred and twenty-one dry femurs from Department of Anatomy, Govt. Medical College, Thiruvananthapuram. Length of femur and the dimensions of its proximal segments were measured using osteometric board and Vernier callipers respectively.

\section{RESULTS}

All the five parameters of the proximal segment show significant relation with length of femur ( $p$ value $<0.001$ ) of which intertrochanteric distance (EF) shows maximum correlation. Regression equations for estimating femoral length from the length of proximal fragments were derived by linear regression analysis.

\section{CONCLUSION}

Regression equations derived in this study are helpful to estimate the stature in medicolegal investigations and in anthropometry.

\section{KEYWORDS}

Femur, Fragmentary Length of Femur, Regression Equation, Stature Estimation.

HOW TO CITE THIS ARTICLE: Sreedhar LSL, Sarasammal SRJ, Oommen AM, et al. Correlation of length of femur with its proximal fragments- A morphometric study. J. Evolution Med. Dent. Sci. 2017;6(70):4975-4978, D0I: 10.14260/Jemds/2017/1080

\section{BACKGROUND}

The stature of an individual is used to establish the identity of a person medicolegally. The stature is calculated from the length of long bones. Length of long bones of lower limb particularly of femur and tibia has a direct correlation to the height of an individual. Damage to long bones is common and in such cases reconstruction of height of the body is very difficult. For the identification of missing persons projection of stature from bones plays an important role. Fragments of long bones are usually the only medicolegal evidence available after post-mortem gnawing by wild animals, mutilation and injuries. The femoral length and stature of individuals are determined from fragments of the upper end of femur, shaft and distal end of the femur.

\section{MATERIALS AND METHODS:}

A descriptive study was conducted in 121 adult dry femurs (Right 54 and left 67) obtained from the Department of Anatomy, Govt. Medical college, Thiruvananthapuram. The bones with gross abnormalities were excluded.

Financial or Other, Competing Interest: None.

Submission 25-07-2017, Peer Review 20-08-2017,

Acceptance 26-08-2017, Published 31-08-2017.

Corresponding Author:

Latha Sreedhar Lekshmy Sreedhar

Bettuvilayil, Karunya 197,

Bharinagar-695011, Medical College, TVPM,

E-mail:drlathals@gmail.com,sujarobert@gmail.com

DOI: $10.14260 /$ jemds $/ 2017 / 1080$

(c) $($ ) $($ )
Six measurements were acquired from femur using osteometric board and Vernier callipers. The following measurements were noted-

a. FL - total length of femur from its upper end to the lower end.

b. ED - maximum width of femur at its upper end, i.e. the distance from most prominent point on the lateral surface of the greater trochanter (GT) to the centre of fovea of the head of femur (Fig. 1).

c. EF - intertrochanteric distance i.e. the distance from most prominent point on the lateral surface of greater trochanter to the tip of lesser trochanter (Fig. 2).

d. GH - width of GT at the upper border i.e. anterior most point on the upper border of GT to the posterior most point on the upper border of GT (Fig. 3).

e. IJ - maximum vertical length of GT, i.e. distance from highest point on the GT at its upper border to the corresponding vertical point on the lower end of GT (Fig. 4).

f. KL - width of GT at its lower end i.e. distance from tip of quadrate tubercle to the most prominent point on the lower end of GT anteriorly (Fig. 5).

Quantitative variables were expressed as minimum, maximum, mean, and standard deviation. Relationship between two quantitative variables were analysed by Pearson correlation. Multivariate linear regression analysis was performed to formulate regression equation for estimation of length of femur from measurements of various 
fragments. A p value $<0.05$ was considered as statistically significant. Data analysis was performed using trial version of SPSS ver. 22.

\section{RESULTS}

The length of 121 femurs (54 right and 67 left) and the lengths of individual segments of all the femur were noted and subjected to statistical analysis and compared. The length of femur ranges from $31.5-54 \mathrm{~cm}$ and the average length of femur was $41.9 \pm 3.4 \mathrm{~cm}$. Descriptive statistics of the measurements of segments of femur are tabulated in Table 1.

Linear regression analysis was done to establish the relationship of femoral length with length of fragments. All the five parameters showed positive correlation with femoral length, with $\mathrm{p}$ value $<0.001$. Thereby equations were derived for the estimation of length of femur from measurements of various fragments like ED, EF, GH, IJ and KL.

Table 2 shows the correlation between length of femur and its proximal segments.

Correlation coefficients ranged from $0.3712-0.569$. The mean discrepancies between the estimated and measured length ranged from 2.81 to 3.24 with $\mathrm{EF}$ (Intertrochanteric distance) and KL (width of GT at its lower end) producing the least and largest discrepancies respectively. Equations were derived for the estimation of length of femur by using univariate and multivariate analysis. Regression model from multivariate analysis reveals that $\mathrm{R}^{2}$ was 0.465 , which means that $46.5 \%$ of the length of femur can be predicted based on the predictive variables (ED, EF, GH, IJ and $\mathrm{KL}$ ). The length of femur can be predicted by the equation:

\section{$F L=17.597+(0.459 \times$ ED $)+(1.418 \times E F)+(0.869 \times$ GH $)+$} $(1.598 \times \mathrm{IJ})+(0.958 \times \mathrm{KL})$

Regression model from univariate analysis revealed EF (intertrochanteric distance) as the best marker for predicting the length of femur. The equations are shown in Table 2.

\begin{tabular}{|c|c|c|c|c|c|}
\hline N & Parameter & $\begin{array}{c}\text { Minimum } \\
\text { Length } \\
\text { in cm }\end{array}$ & $\begin{array}{c}\text { Maximum } \\
\text { Length in } \\
\text { cm }\end{array}$ & Mean & $\begin{array}{c}\text { Standard } \\
\text { Deviation }\end{array}$ \\
\hline 121 & FL & 31.5 & 54 & 41.9 & 3.4 \\
\hline 121 & ED & 1.9 & 10.04 & 8.02 & 1.11 \\
\hline 121 & EF & 4.01 & 8.23 & 5.81 & 0.78 \\
\hline 121 & GH & 2.31 & 7.42 & 3.44 & 0.59 \\
\hline 121 & IJ & 2.83 & 5.78 & 3.95 & 0.56 \\
\hline 121 & KL & 0.22 & 4.52 & 3.24 & 0.59 \\
\hline \multicolumn{7}{|c|}{ Table 1. Descriptive Statistics of Measurements } \\
of the Femur
\end{tabular}

ED (Maximum width of femur at its upper end), EF (Intertrochanteric distance), GH (Width of greater trochanter at its upper end), IJ (maximum vertical length of greater trochanter), KL (width of greater trochanter at its lower end),

\begin{tabular}{|c|c|c|c|c|c|}
\hline $\begin{array}{c}\text { Para- } \\
\text { meter }\end{array}$ & Equation & $\mathbf{R}$ & $\mathbf{R}^{2}$ & Se & p value \\
\hline ED & $\begin{array}{c}\text { FL=31.648+ } \\
(\mathrm{ED} \times 1.28)\end{array}$ & 0.416 & 0.173 & 3.1121 & $<0.001$ \\
\hline $\mathrm{EF}$ & $\begin{array}{c}\mathrm{FL}=27.359+ \\
(\mathrm{EF} \times 2.503)\end{array}$ & 0.569 & 0.324 & 2.8149 & $<0.001$ \\
\hline $\mathrm{GH}$ & $\begin{array}{c}\mathrm{FL}=34.558+ \\
(\mathrm{GH} \times 2.14)\end{array}$ & 0.371 & 0.138 & 3.1788 & $<0.001$ \\
\hline $\mathrm{IJ}$ & $\begin{array}{c}\text { FL=31.706+ } \\
(\mathrm{IJ} \times 2.587)\end{array}$ & 0.422 & 0.178 & 3.1041 & $<0.001$ \\
\hline $\mathrm{KL}$ & $\begin{array}{c}\text { FL=35.991+ } \\
(\mathrm{KL} \times 1.8330)\end{array}$ & 0.390 & 0.102 & 3.2440 & $<0.001$ \\
\hline \multicolumn{6}{|c|}{ Table 2. Shows the Correlation between Length of } \\
\hline
\end{tabular}

ED (Maximum width of femur at its upper end), EF (Intertrochanteric distance), GH (Width of greater trochanter at its upper end), IJ (Maximum vertical length of greater trochanter), KL (Width of greater trochanter at its lower end). R - Correlation Co-efficient, $\mathrm{R}^{2}$ - Co-efficient of Correlation, SE- standard error of estimate.

\begin{tabular}{|c|c|}
\hline Authors & Mean Total Length of Femur(FL) \\
\hline Mc Kern and Steel $\mathbf{1}^{\mathbf{1}}$ & $44.90 \pm 1.71 \mathrm{~cm}$ \\
\hline AG Shroff $^{2}$ & $42.01 \pm 2.75 \mathrm{~cm}$ \\
\hline Sandeep Singh et al $^{\text {Sarzoo Desai }}{ }^{\mathbf{~}}$ et al & $43.26 \pm 2.67 \mathrm{~cm}$ \\
\hline Sarota Solan $^{\text {Shweta }}$ & $43.71 \pm 2.80 \mathrm{~cm}$ \\
\hline Our study & $43.48 \pm 2.6 \mathrm{~cm}$ \\
\hline \multicolumn{2}{|c|}{ Table 3. Shows Comparison of FL between } \\
Present Work and that of Others \\
\hline
\end{tabular}

\begin{tabular}{|c|c|}
\hline Our study & $\mathrm{FL}=27.359+(2.503 \times \mathrm{EF})$ \\
\hline Ajay M Parmar & $\mathrm{FL}=23.71+(2.93 \times \mathrm{P} 2) \mathrm{P} 2$ \\
\hline Laxman Khanal & $\mathrm{FL}=37.01+(0.97 \times \mathrm{ITC})$ \\
\hline \multicolumn{2}{|c|}{ Table. 4 Comparison of Linear Equations between } \\
Different Studies
\end{tabular}

EF, P2, ITC represent intertrochanteric distance

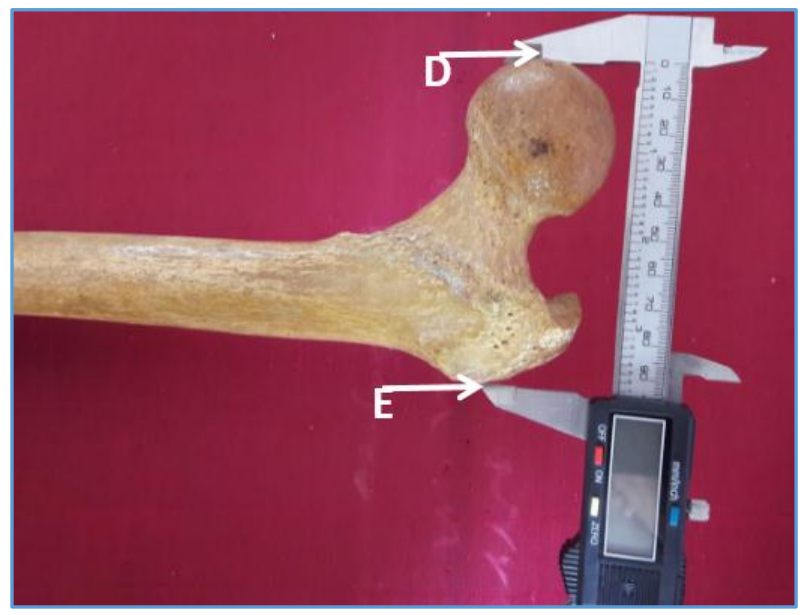

Figure 1. E D-Maximum Width of the Upper End of Femur

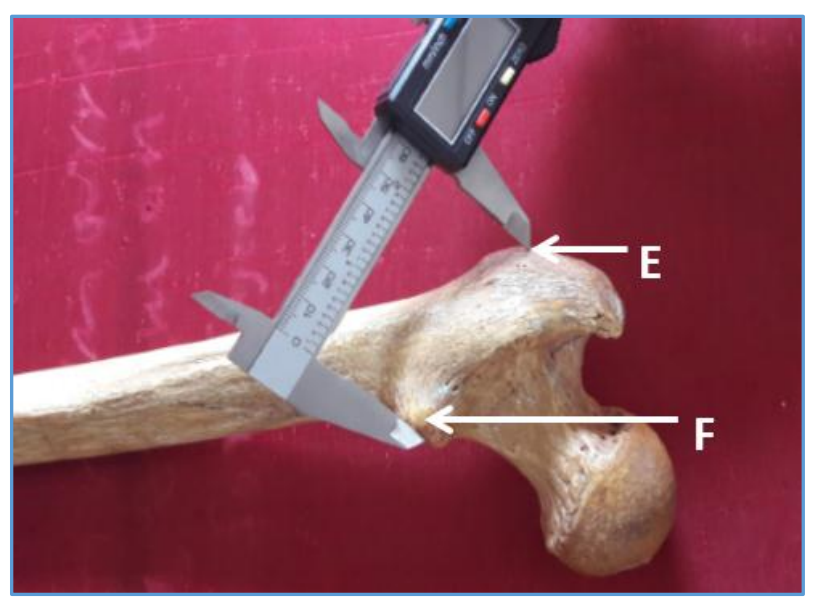

Figure 2. EF - Intertrochanteric Distance 


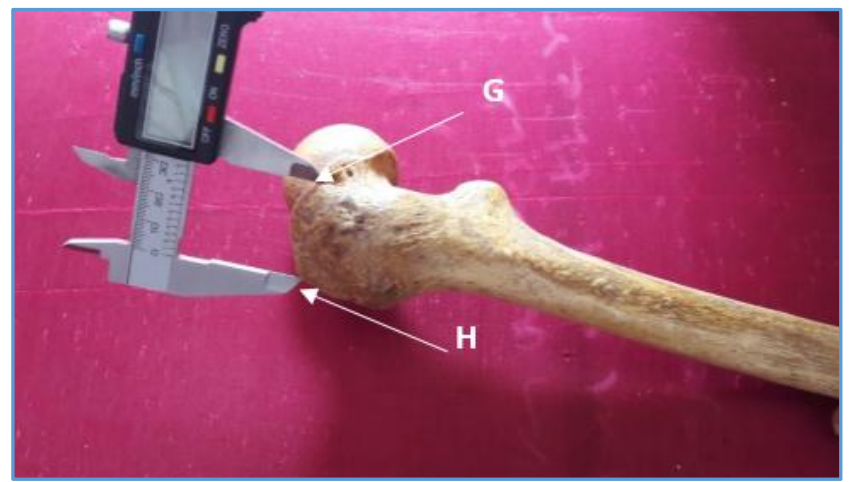

Figure 3. GH - Width of Greater Trochanter at its Upper End

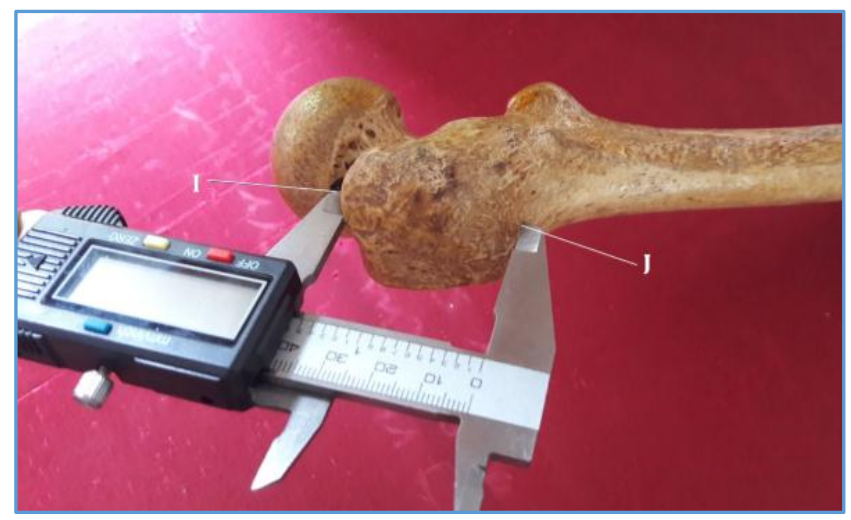

Figure 4. I J - Maximum Vertical Length of Greater Trochanter

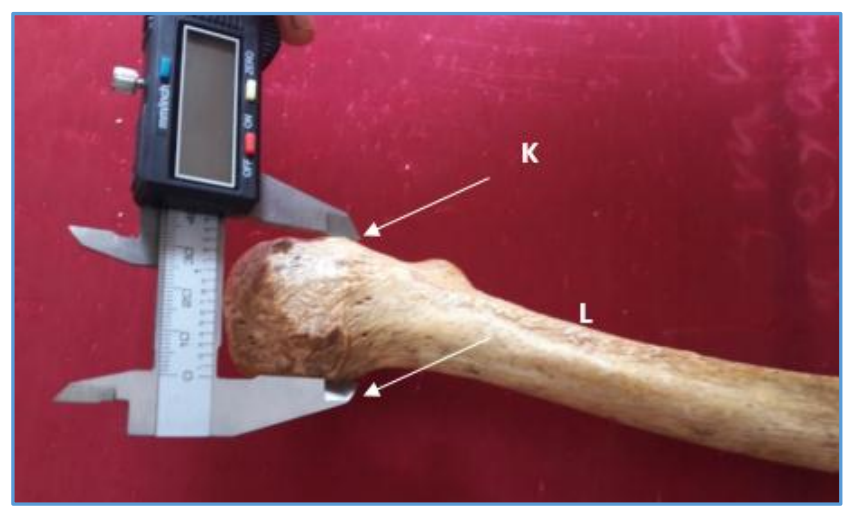

Figure 5. K L - Width of Greater Trochanter at its Lower End

\section{DISCUSSION}

Estimation of stature or sex from the long bones plays an important role in identification of bodies. For estimation of stature from long bone fragments, the length of long bones should be estimated first. Length of long bones is then employed in the stature formulae. The lengths of radius (Holla ${ }^{4}$ et al, 1996), lengths of ulna (Suja ${ }^{5}$ et al), humerus (Selvaraj6 et al, 1998), and femur (Prasad7 et al, 1996) has been estimated using bony markers (bony fragments). Dupertius $^{\mathbf{8}}$ et al has reported that long bones of lower limb give closer estimates of height compared to upper limb bones. Individually and collectively femur and the tibia are the most important components of height. Therefore, the best assessment of height is obtained from regression formulae derived from femoral and tibial length. Trotter and Glesser 9 recommended the use of lower limb bones against upper limb for the estimation of stature because they are the weight bearing bones. They also derived regression formulae for estimation of stature from length of long bones. Shweta Solan ${ }^{10}$ et al in a study on South Indian population divided femur into 5 segments, the proportion of segments to the total length was calculated which helps in stature estimation. Ajay M Parmar et al11 has observed the strongest correlation of femoral length with the distance between the apex of greater trochanter to the lower margin of lesser trochanter. In our study, the femoral length correlates best with EF (intertrochanteric distance). Sandeep Singh et al12 derived a regression equation by measuring femoral length and intertrochanteric crest length. Gehring KD et al ${ }^{13}$ estimated femoral length from proximal fragment containing head and neck. Laxman Khanal et al ${ }^{\mathbf{1 4}}$ found a linear relation between femur length and intertrochanteric crest length, neck circumference, neck length and depth of condyles. Femoral length was reconstructed using subtrochanteric transverse diameter, vertical and transverse head diameter in a study by Jubilant ${ }^{15}$ et al.

In this study, five measurements were acquired from proximal end of femur and assessed for prediction of femoral length using linear regression analysis. The measurements include FL (femoral length), ED (maximum width of femur at its upper end), EF (intertrochanteric distance), GH (width of greater trochanter at its upper end), IJ (Maximum vertical length of greater trochanter), KL (width of greater trochanter at its lower end). All the parameters show significant positive correlation with length of femur ( $p$ value $<0.001$ ). EF (intertrochanteric distance) shows maximum correlation. This is in accordance with the study of Ajay M Parmar et al. Table 3 shows comparison of FL between present work and that of others. Table 4 shows comparison of linear regression equations derived in different studies based on intertrochanteric distance.

\section{CONCLUSION}

This study results in the development of specific osteometric data designed for stature determination from femurs of South Indian population. The regression equations derived from this study is helpful for the reconstruction of length of femur from its proximal fragments. These values help to predict the stature of an individual in the South Indian population and has potential application in physical and forensic anthropology.

\section{ACKNOWLEDGEMENTS}

The authors thank Dr Renuka K, Professor and HOD, Department of Anatomy, Govt. Medical College, Thiruvananthapuram; Dr Rema, Professor and HOD, Department of Forensic Medicine, Govt. Medical College, Thiruvananthapuram and Mr. Jayakumar P who helped in statistical analysis.

\section{REFERENCES}

[1] Steele DG, Mckern TW. A method for assessment of maximum long bone length and living stature from fragmentary long bones. Am J Phys Anthropol 1969;31(2):215-27.

[2] Shroff AG, Panse AA, Diwan CV. Estimation of length of femur from its fragments. Journal of Anatomical Society of India 1999;48(1):1-5. 
[3] Desai S. Estimation of length of femur from the length of its fragments. JEMDS 2013;2(29):5450-7.

[4] Holla SJ, Vettivel S, Chandi G. Bony markers at the distal end of the radius for estimating the handedness and radial length. Ann Anat 1996;178(2):191-5.

[5] Prasannankumar S, Selvaraj KG, Rabi S, et al. Estimation of length of the ulna from the bony markers of the proximal end in South Indian population. Eur J Anat 2010;14(2):67-73.

[6] Selvaraj KG, Vettvel S, Indrasingh I, et al. Handedness identification from intertubercular sulcus of the humerus by discriminant function analysis. Forensic Sci Int 1998;98(1-2):101-8.

[7] Prasad R, Vettivel S, Jayaseelan L, et al. Reconstruction of femur length from markers of its proximal end. Clin Anat 1996;9(1):28-33.

[8] Dupertuis CW, Hadden JA. On the reconstruction of stature from long bones. Am J Phys Anthropol 1951;9(1):15-53.

[9] Trotter M, Gleser GC. Corrigenda to estimation of stature from long limb bones of American whites and Negroes American journal physical anthropology (1952). Am J Phy Anthropol 1977;47(2):355-6.
[10] Solan S, Kulkrni R. Estimation of total length of femur from its fragments in South Indian population. Journal of Clnical and Diagnostic Research 2013;7(10):2111-5.

[11] Parmar AM, Shah KP, Goda J, et al. Reconstruction of total length of femur from its proximal and distal fragments. Int J Anat Res 2015;3(4):1665-68.

[12] Singh S, Nair SK, Anjankar V, et al. Regression equation for estimation of femur length in central Indians from intertrochanteric crest. J Indian Acad Forensic Med 2013;35(3):223-6.

[13] Gehring KD, Graw M. Determining body height by femur and femoral fragments. Arch Kriminol 2001;207(5-6):170-80.

[14] Khanel L, Shah S, Koirala S. Estimation of total length of femur from its proximal and distal segmental measurements of disarticulated femur bones of Nepalese population using regression equation method. Journal of Clinical and Diagnostic Research 2017;11(3):HC01-5.

[15] Abluedu JK, Offei EB, Osabuty CK. Reconstruction of femur length from fragmentary femora. Anat Cell Biol 2016;49(3):206-9. 